\title{
Coccidial infection does not influence preening behavior in American goldfinches
}

\author{
Adrian Surmacki • Geoffrey E. Hill
}

Received: 29 April 2013 /Revised: 24 July 2013 / Accepted: 5 August 2013 / Published online: 28 August 2013

(C) The Author(s) 2013. This article is published with open access at Springerlink.com

\begin{abstract}
Preening behavior in birds is important for the maintenance of thermoregulatory and ornamental functions of plumage. It has been repeatedly demonstrated that birds trade off time between plumage maintenance and other activities. However, the condition-dependent constraints of preening remain virtually unstudied. Here, we present the first experimental test of the hypothesis that intestinal parasite infection impairs preening activity. We studied male American goldfinches (Spinus tristis), a species with carotenoid-based plumage coloration. Following pre-alternate (spring) molt, we manipulated the health of males by infecting some birds with Isospora spp. coccidia and keeping others free of the infection. Although the goldfinches increased preening throughout the captive period, we found no significant effect of coccidial treatment on preening behavior. The effect of coccidia on plumage maintenance may be more pronounced under natural conditions where birds have limited access to food and engage in more activities that might limit time available for preening.
\end{abstract}

Keywords Feather soiling · Feather grooming $\cdot$ Parasites · Infection $\cdot$ Health

\section{Introduction}

Plumage maintenance is an important behavior among birds, accounting for about $9 \%$ of the daily time budged (Cotgreave and Clayton 1994; Walther and Clayton 2005). The primary

\footnotetext{
A. Surmacki · G. E. Hill

Department of Biological Sciences, Auburn University,

331 Funchess Hall, Auburn, AL 36849, USA

A. Surmacki $(\square)$

Department of Avian Biology and Ecology, Faculty of Biology,

Adam Mickiewicz University, Umultowska 89,

61-614 Poznań, Poland

e-mail: adrian@amu.edu.pl
}

functions of preening include: controlling ectoparasites load (Clayton et al. 2010), removing dirt and detritus (Lenouvel et al. 2009; Griggio et al. 2010), spreading preen wax over the surface of feathers (Moyer et al. 2003), and keeping feathers properly positioned. All of these activities are crucial for the maintenance of thermoregulatory function of plumage, which might be altered if the physical condition of feathers is disturbed either by soiling load, keratin-eating parasites, or disorder. Plumage maintenance can also help maintain plumage coloration. In many bird species, females use male coloration as a cue during mate choice (reviewed in Hill 2006). Ornamental plumage coloration can be compromised by soiling (e.g., Surmacki and Nowakowski 2007; Lenouvel et al. 2009; Griggio et al. 2010), and ectoparasites (Moreno-Rueda 2005) or enhanced by preen oil (e.g., López-Rull et al. 2010).

Feather maintenance is believed to be a time- and energyconsuming behavior (Cotgreave and Clayton 1994; Walther and Clayton 2005). Birds must trade off time and energy between preening and other behaviors such as foraging or scanning for predators (Redpath 1988; Cucco and Malacarne 1997; Randler 2005). Consequently, we may expect that any alteration of physiological condition may impose negative effects on preening activity. Surprisingly, this idea has been tested only once, using juvenile apapanes (Himatione sanguinea, Yorinks and Atkinson 2000). Individuals experimentally infected with malaria spent significantly less time preening than did healthy birds. Infected individuals also showed a reduction in activity, body mass, and fat stores (Yorinks and Atkinson 2000).

Here, we experimentally tested the hypothesis that parasite infection affects preening behavior in male American goldfinches (Spinus tristis), a sexually dichromatic songbird. Male goldfinches have bright-yellow carotenoid-based plumage coloration (McGraw et al. 2001) that females assess during mate choice (Johnson et al. 1993). We manipulated parasite infection status of birds by either infecting them with coccidia (Isospora sp.) or by curing them of coccidiosis with medicine. 
Coccidia are common intestinal parasite of many songbirds including house finches, Carpodacus mexicanus (Brawner et al. 2000). Their sporozoites feed on the epithelium of the small intestine, leading to significant impairment of absorption of various components of food (Hõrak et al. 2004). To date, the effect of coccidia infection on preening has not been tested but coccidiosis is known to affect sexual display behavior in birds (e.g., Costa and Macedo 2005; Aguilar et al. 2008) and anti-predator behavior in mammals (Voŕíšek et al. 1998). Consequently, we predicted that infected individuals would spend less time preening.

\section{Material and methods}

\section{General}

We captured 57 wild male American goldfinches on the campus of the Auburn University in April 2010 using wire mesh traps baited with thistle seeds (see Hill (2002) for trapping method details). We registered standard biometric measurements: body mass $(0.1 \mathrm{~g})$, tarsus $(0.01 \mathrm{~mm})$, bill $(0.01 \mathrm{~mm})$, wing $(0.5 \mathrm{~mm})$, and tail length $(1 \mathrm{~mm})$. Additionally, we collected $10-15$ breast feathers from each bird before coccidia treatment and at the end of the experiment for ectoparasite examination. We estimated the age of birds as "after second year" (ASY) or "second year" (SY) based on plumage characters (Pyle 1997). We randomly divided the birds into four groups of 13,16, 14, and 14 birds. The proportions of the two age classes (ASY/SY) in each cage were as follows: $11 / 2,14 / 2,12 / 2$, and 12/2 such that the total number of birds and proportion of ASY to SY were similar in all cages (chi-square test: $\chi^{2}=0.16, d f=3, p=0.98$; chi-square test: $\chi^{2}=0.05, d f=3, p=0.99$, respectively). There were no significant differences between groups of birds with regard to the linear biometric measures (see above) and body mass at the beginning of the experiment (mass: ANOVA, $d f=3.53$, $F=0.43, p=0.74$; tarsus: ANOVA, $d f=3.53, F=0.88, p=$ 0.46 ; bill: ANOVA, $d f=3.53, F=1.33, p=0.28$; wing: Kruskal-Wallis ANOVA, $d f=3.53, F=5.97, p=0.11$; tail: Kruskal-Wallis ANOVA, $d f=3.53, F=3.63, p=0.30$ ). We randomly choose ten birds (five from medicated and five from infected group) on which to assess ectoparasites. We examined the collected feathers of these ten birds under dissection microscope $(\times 20)$ to score potential ectoparasites (presumably feather lice). The only arthropods found of feathers were feather mites. There were no significant differences in numbers of mites between infected and medicated groups in pretreatment samples (infected: median $=1, \mathrm{Q}_{25-75}=0-1$; medicated: median $=2, \mathrm{Q}_{25-75}=0-2$; Mann-Whiney test, $U=10.5$, $p=0.75$ ) and posttreatment samples (infected: median $=0$, $\mathrm{Q}_{25-75}=0-0$; medicated: median $=0, \mathrm{Q}_{25-75}=0-1$; MannWhiney test, $U=10.0, p=0.68$ ). We housed each group in outdoor cages $(3.7 \times 1.5 \times 2.4 \mathrm{~m})$ with wire mesh walls and ceilings and concrete floors. Approximately one half of the ceiling was covered with a sheet of plywood to provide shade and shelter from weather. Each cage had five wooden stick perches for a total length of $5.5 \mathrm{~m}$. We individually marked birds with numbered aluminum bands and a combination of two color bands. We fed birds with sunflower seed chips, thistle seeds, and water ad libitum. Until the beginning of the experiment in July (see below), all birds were provided with sulfadimethoxine, an antibiotic known to protect captive wild birds against coccidial infection (Brawner et al. 2000). Moreover, throughout the experiments, all birds were maintained continuously on the antibiotic drug tylosin tartrate $(0.3 \mathrm{mg} / \mathrm{ml})$. This drug suppresses the lethal bacterium Mycoplasma gallisepticum (Nolan et al. 2000) and prevents proliferation of this bacterium in captive flocks. At the beginning of the experiment, all males had completed their spring pre-alternate molt-growing bright-yellow body plumage.

\section{Experiment design}

We randomly assigned cages of birds to medicated (two cages) or infected (two cages) treatment groups. Birds in both groups were treated with sulfadimethoxine since they were caught (April) until beginning of experiment (July 13) to exclude effects of coccidia during the period when they were adjusting to captivity. Birds in the infected group were taken off of sulfadimethoxine treatment and infected with coccidian by addition of Isospora sp. oocysts to drinking water (see below for details). Thus, we created two distinct groups of birds: medicated with no detectable coccidia infection and infected in which the prevalence of coccidia was $100 \%$ (see next section for details). The experiment started on July 13 (day " 0 "), when coccidiostatic medicine was terminated in treatment birds and lasted 33 days. Between the eighth and third days preceding the start of experiment, we scored grooming behavior of birds ( 5 days in total). The second score of grooming behavior took place on 34th and 37th day of experiment (4 days in total). We failed to quantify preening behavior for four males; therefore, the total sample size used in analysis was 53 .

Earlier studies indicated that sulfadimethoxine suppresses, but does not eliminate, isosporan coccidiosis (Brawner et al. 2000). Consequently, several days after the treatment with sulfa drugs stopped, birds should begin to pass oocysts (Brawner et al. 2000). We randomly collected feces from the floors of cages of treatment groups on the 10th and 14th days of the experiment and found oocysts present in only $50 \%$ of feces tested. Therefore, on days 15th and 16th of the experiment, we infected drinking water with powdered feces collected from wild birds $(0.014 \mathrm{~g}$ of per $100 \mathrm{ml})$. Feces were collected during the afternoon when the coccidia exertion is the highest (Brawner and Hill 1999). This method mimics real 
infection in the wild. Coccidian of the genus Isospora is transferred from infected to uninfected birds by coccidian oocysts passing in feces that are then ingested by foraging birds (Box 1981).

The coccidia manipulation protocol may have resulted in $\sim 50 \%$ of birds (see above), being exposed to infection for 33 days while the rest infected for 18 days. Despite this divergence, we are confident that our experiment design allowed enough time for changes in grooming to be visible. In Dolnik and Hoi's (2010) study, House Sparrows showed changes in aggressive behavior 9-10 days after reinfection with coccidia. In another study on Eurasian Blackbirds, the peak number of oocysts in feces occurred on tenth day after infection, and then declined (Filipiak et al. 2009).

\section{Coccidian infection analysis}

We collected feces from all birds on 9 and 11 August (days 27 th and 29th of the experiment), between 1700 and 2000 hours. For fecal collection, we temporarily housed goldfinches individually in small $(0.5 \times 0.5 \times 0.5 \mathrm{~m})$ cages with mesh bottoms between. We placed a steel pan lined with wet paper towels beneath each cage to collect feces. We then moved feces to $5-\mathrm{ml}$ vials containing $2 \mathrm{ml}$ of $2.2 \%$ potassium dichromate and ground them with a wooden dowel. Vials remained open for 3 days to allow oocysts to sporulate. Then, vials were tightly closed and refrigerated until oocyst' counting. We measured the mass (to the nearest $0.001 \mathrm{~g}$ ) of each vial containing potassium dichromate immediately before and after feces were added to the vials. This procedure allowed us to determine the mass of fresh feces as the difference between masses of empty and feces containing vials.

We scored coccidian oocysts using a hemocytometer under $\times 100$ magnification by counting all oocysts visible within a grid of nine $1 \times 1 \mathrm{~mm}^{2}$. For each bird sample, we averaged four counts of oocysts. Before each count was made, the vial was vigorously shaken to mix the contents. To calculate the total number of oocysts within $1 \mathrm{~g}$ of feces, we extrapolated average score from hemocytometer grid area volume $(900 \mathrm{nl})$ to the whole sample volume $(2 \mathrm{ml})$. The number of oocysts per $1 \mathrm{~g}$ of feces was positively correlated with mean oocyst number per feces sample $\left(r_{\mathrm{s}}=0.82, p<0.01, n=19\right)$ but not with feces mass $\left(r_{\mathrm{s}}=\right.$ $-0.40, p=0.09, n=19)$. Because precise calculation of the number oocyst per $1 \mathrm{~g}$ of feces was not possible in all cases (see "Results" for more details), in subsequent analyses, we used the number of oocyst per feces sample as a measure of coccidia abundance.

The coccidia oocysts were distinguished as Isospora spp. by Dr. Christine A. Sundermann (Auburn University) under a microscope $(\times 1,000)$.
Preening behavior

We used a protocol modified from Lenouvel et al. (2009) to quantify grooming behavior. We sampled the behavior of males in random order 60 times for $10 \mathrm{~s}$ intervals. Half of the behavioral samples $(n=30)$ were gathered in the morning (0730-1100 hours) and the other half $(n=30)$ in the afternoon (1400-1830 hours). A.S. observed birds through small twoway mirrors mounted in the wall of building adjacent to cages and recorded the following grooming behaviors: preening (the bird takes a feather in its beak), ruffling (the bird shakes entire plumage), and scratching (the bird scratches a part of its plumage with a foot). The maximum score that a male could get for a particular grooming behavior was 60 (grooming observed in all $10 \mathrm{~s}$ samples).

Statistical analysis

We tested the normality of the data distribution using ShapiroWilk tests. Preening scores were $\log _{10}$ transformed to obtain a normal distribution (raw data: Shapiro-Wilk test, $W=0.95, p=$ 0.02; transformed data: Shapiro-Wilk test, $W=0.97, p=0.17$ ). Changes in preening activity were analyzed using General Linear Mixed Models (GLMM) with Measurement (preening at pre- and posttreatment phases) and Treatment (medicated or infected) as fixed factors. To test whether changes in preening depended on infection level, Measurement $\times$ Treatment interaction was included in the model. Because both medicated and infected birds were kept in two cages, we included cage identity as a random factor.

We performed a priori power test to assess sample size needed to confidently test the hypothesis about the effect coccidia infection on changes in preening activity (Measurement $\times$ Treatment interaction). We used G*Power 3.1.7 software (Faul et al. 2007) with the following settings: effect size $=0.25, \alpha=0.05$, nonsphericity correction $\varepsilon=1$. The sample size needed to have an $80 \%$ chance of detecting a difference if such a difference existed is 34 , which is below the sample size used in the study $(n=53)$.

\section{Results}

We found coccidian oocysts in all fecal samples collected from infected males at the end of the experiment. Median number of oocysts per $1 \mathrm{~g}$ of fresh feces was $14 \times 10^{5}$ $\left(Q_{25-75 \%}=0.97 \times 10^{5}-34 \times 10^{5}, n=19\right)$. For eight birds, the mass of feces was too low to measure, nevertheless, even those samples contained oocysts. Therefore, we also calculated the mean oocyst number per feces sample (see "Material and methods"). Median oocyst number per feces sample for all infected males was $44\left(\mathrm{Q}_{25-75 \%}=2.50-93.00, n=27\right)$. Zero 
Table 1 Results of GLMM analysis of the effect of experimental infection with Isospora coccidia on the American goldfinches preening behavior

\begin{tabular}{lllllllll}
\hline Variable & $F$ & $\mathrm{~N}$ & $\mathrm{D} d f$ & $P$ & Estimate $\pm \mathrm{SE}$ & $\begin{array}{l}\text { Wald } \\
Z\end{array}$ & $P$ \\
& & $d f$ & & & & & \\
\hline Measurement & 8.95 & 1 & 100.47 & $<0.01$ & & & \\
Treatment & 0.68 & 1 & 0.68 & 0.53 & & & \\
$\begin{array}{l}\text { Measurement } \times \\
\quad\end{array} \quad 0.06$ & 1 & 100.47 & 0.81 & & & \\
$\quad \begin{array}{l}\text { Treatment } \\
\text { Cage }\end{array}$ & & & & & $0.003 \pm 0.004$ & 0.69 & 0.49 \\
\hline
\end{tabular}

Measurement of the same individual (preening at pre- and posttreatment phases) and Treatment (medicated or infected) were entered as fixed factors and Cage as a random factor

oocysts were found in samples collected from medicated birds.

Birds increased preening intensity at the end of the experiment (Table 1, Fig. 1). The magnitude of change in preening behavior did not differ between treatment groups, and variation in preening activity was not related to cage identity (Fig. 1, Table 1).

\section{Discussion}

We predicted that goldfinches infected with Isospora coccidia would devote less time to plumage maintenance. The results of our experiment did not support our prediction. In the course of the study, all of the goldfinches increased preening intensity but infection had no significant effect on preening.
Fecal analysis confirmed that we succeeded in creating two distinct groups: healthy birds that did not shed oocysts (prevalence $0 \%$ ) and infected birds with $100 \%$ prevalence of coccidia. According to a previous study on a related species (Brawner and Hill 1999), mean level of infection in our birds should be regarded as massive. Coccidiosis is a serious, chronic intestinal infection of songbirds (Duszynski et al. 2000). Hõrak et al. (2004) found that coccidia significantly depressed serum albumin, triglycerides, and fat-soluble antioxidants (carotenoids and vitamin E) in closely related greenfinches (Carduelis chloris). In captivity, American goldfinches are very sensitive to coccidiosis (McGraw and Middleton 2009). Wild birds kept in aviaries without coccidiostatic medicines often die of coccidiosis within few weeks (G. E. Hill not published observation, McGraw and Hill 2000). Male American goldfinches that have coccidial infection during molt grow yellow breast feathers that are less bright than males that are not infected (McGraw and Hill 2000).

Our prediction that coccidial infection would affect feather maintenance behavior was based on previous surveys suggesting that coccidia influence the activity level of birds. Correlational and experimental studies on blue-black grassquits (Volatinia jacarina) demonstrate that coccidial infection negatively influences the frequency of courtship leaps (Costa and Macedo 2005; Aguilar et al. 2008). House Sparrows (Passer domesticus) infected with Isospora michaelbakeri tend to experience a lower hierarchy position in captive flocks (Dolnik and Hoi 2010). The behaviors related to coccidial infection in these previous studies, however, did not necessarily compromise the survival of the infected bird. It seems likely that when they become ill, individuals
Fig. 1 Mean $( \pm 95 \%$ CL) preening activity at preening at pre- and posttreatment phases. Open squares are medicated and filled squares infected males

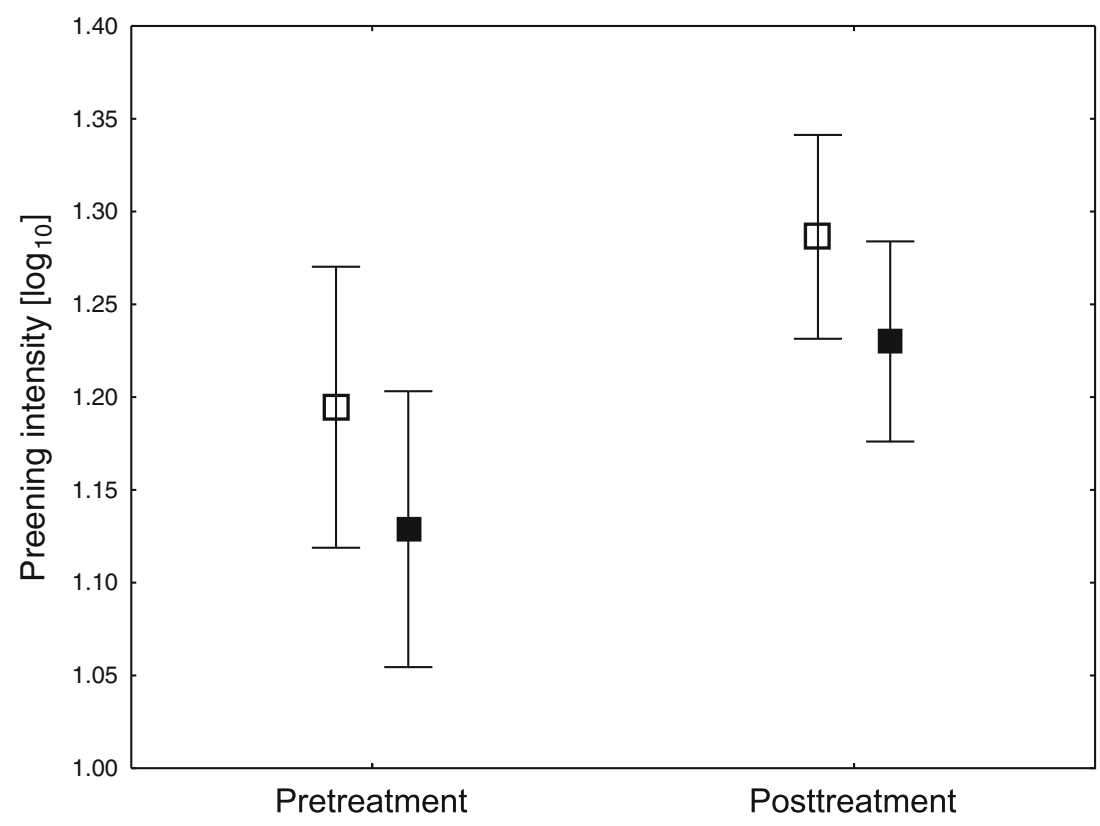


prioritize those physiological processes and behaviors that are needed to help them cope with the parasite and recover. Maintaining plumage in good condition seems likely to be one of the prioritized behaviors. Moreover, social behavior and sexual display are probably more energetically demanding than preening, which makes them more sensitive to coccidiosis.

Another possibility is that captive conditions buffered the effects of infection on preening behavior. Unlike wild goldfinches, birds used in this experiment did not have to trade off time between plumage maintenance and other vital activities like predator avoidance, food searching, courtship, or parental care. The results of our study do not exclude the possibility that coccidia infection diminishes preening behavior when resources or time are limiting. Future research should be performed in more natural conditions in which the effects of coccidia on the preening behavior might be stronger.

Acknowledgments This project was funded by NSF Grant 0923088 to Geoffrey E. Hill. Adrian Surmacki has been financially supported by Polish Ministry of Science and Higher Education as a part of "Support for International Mobility of Scientists Program" (553/MOB/2009/0). Special thanks are due to Margarita Rios-Kessler who helped with processing birds at all stages of the study and maintained captive flocks. Christine A. Sundermann generously shared her vast knowledge and experience about processing coccidia samples. Constructive discussions with Mark Liu helped to shape experimental design. Members of Geoffrey Hill and Wendy Hood laboratories as well as Lynn Siefferman provided many helpful comments on the project.

Open Access This article is distributed under the terms of the Creative Commons Attribution License which permits any use, distribution, and reproduction in any medium, provided the original author(s) and the source are credited.

\section{References}

Aguilar TM, Maia R, Santos ES, Macedo RH (2008) Parasite levels in blue-black grassquits correlate with male displays but not female mate preference. Behav Ecol 19:292-301

Box ED (1981) Isospora as an extraintestinal parasite of passerine birds. J Protozool 28:244-246

Brawner WR III, Hill GE (1999) Temporal variation in shedding of coccidial oocysts: implications for sexual-selection studies. Can J Zool 77:347-350

Brawner WR III, Hill GE, Sundermann CA (2000) Effects of coccidial and mycoplasmal infections on carotenoid-based plumage pigmentation in male House Finches. Auk 117:952-963

Clayton DH, Koop JAH, Harbison CW, Moyer BR, Bush SE (2010) How birds combat ectoparasites. Open Ornithol J 3:41-71

Costa FJV, Macedo RH (2005) Coccidian oocyst parasitism in the blueblack grassquit: influence on secondary sex ornaments and body condition. Anim Behav 70:1401-1409

Cotgreave P, Clayton DH (1994) Comparative analysis of time spent grooming by birds in relation to parasite load. Behaviour 131:171-187

Cucco M, Malacarne G (1997) The effect of supplemental food on time budget and body condition in the black redstart Phoenicurus ochruros. Ardea 85:211-221

Dolnik O, Hoi H (2010) Honest signalling, dominance hierarchies and body condition in House Sparrows Passer domesticus (Aves: passeriformes) during acute coccidiosis. Biol J Linn Soc 99:718-726
Duszynski DV, Couch L, Upton SJ (2000) The Coccidia of the World. KState Parasitology Laboratory. http://www.ksu.edu/parasitology/ worldcoccidia. Accessed 29 April 2013

Faul F, Erdfelder E, Lang A-G, Buchner A (2007) G*Power 3: a flexible statistical power analysis program for the social, behavioral, and biomedical sciences. Behav Res Meth 39:175-191

Filipiak L, Mathieu F, Moreau J (2009) Caution on the assessment of intestinal parasitic load in studying parasite-mediated sexual selection: the case of Blackbirds coccidiosis. Int J Parasitol 39:741-746

Griggio M, Hoi H, Pilastro A (2010) Plumage maintenance affects ultraviolet colour and female preference in the budgerigar. Behav Proc 84:739-744

Hill GE (2002) A red bird in a brown bag. The function and evolution of colorful plumage in the House Finch. Oxford University Press, New York

Hill GE (2006) Female choice for ornamental coloration. In: Hill GE, McGraw KJ (eds) Bird coloration. Vol. 2. Function and evolution. Harvard University Press, Cambridge MA, pp 137-200

Hõrak P, Saks L, Karu U, Ots I, Surai PF, McGraw KJ (2004) How coccidian parasites affect health and appearance of greenfinches. $\mathrm{J}$ Anim Ecol 73:935-947

Johnson K, Dalton R, Burley N (1993) Preference of female American goldfinches (Cardualeis tristis) for natural and artificial male traits. Behav Ecol 4:138-143

Lenouvel P, Gomez D, Théry M, Kreutzer M (2009) Do grooming behaviours affect visual properties of feathers in male domestic canaries, Serinus serinus? Anim Behav 77:1253-1260

López-Rull I, Pagán I, Garcia CM (2010) Cosmetic enhancement of signal coloration: experimental evidence in the house finch. Behav Ecol 21:781-787

McGraw KJ, Hill GE (2000) Differential effects of endoparasitism on the expression of carotenoid- and melanin-based ornamental coloration. Proc Roy Soc B 267:1525-1531

McGraw KJ, Middleton AL (2009) American Goldfinch (Spinus tristis). In: Poole A (ed) The birds of North America Online. Cornell Lab of Ornithology, Ithaca NY

McGraw KJ, Hill GE, Stradi R, Parker RS (2001) The influence of carotenoid acquisition and utilization on the maintenance of species-typical plumage pigmentation in male American Goldfinches (Cardualis tristis) and Northern Cardinals (Cardinalis cardinalis). Physiol Biochem Zool 74:843-852

Moreno-Rueda G (2005) Is the white wing-stripe of male house sparrows passer domesticus an indicator of the load of mallophaga? Ardea 93:109-114

Moyer BR, Rock AN, Clayton DH (2003) Experimental test of the importance of preen oil in rock doves (Columba livia). Auk 120:490-496

Nolan PM, Duckworth RA, Hill GE, Roberts SR (2000) Maintenance of a captive flock of house finches free of infection by Mycoplasma gallisepticum. Avian Dis 44:948-952

Pyle P (1997) Identification Guide to North American Birds, Part I: Columbidae to Ploceidae. Slate Creek Press, Bolinas

Randler C (2005) Vigilance during preening in Coots Fulica atra. Ethology 111:169-178

Redpath S (1988) Vigilance levels in preening dunlin Calidris alpina. Ibis 130:555-557

Surmacki A, Nowakowski JK (2007) Soil and preen waxes influence the expression of carotenoid-based plumage coloration. Naturwissenschaften 94:829-835

Voríšsek P, Votýpka J, Zvára K, Svobodová M (1998) Heteroxenous coccidia increase the predation risk of parasitized rodents. Parasitology 117:521-524

Walther BA, Clayton DH (2005) Elaborate ornaments are costly to maintain: evidence for high maintenance handicaps. Behav Ecol 16:89-95

Yorinks N, Atkinson CT (2000) Effects of malaria on activity budgets of experimentally infected juvenile apapane Himatione sanguine. Auk 117:731-738 